\title{
A Case Report on the Correction of Contraocclusion due to Improper Determination of Full Denture Position
}

\author{
by \\ I. SUMI, ${ }^{*}$ H. OKI, ${ }^{*}$ M. KOYAMA, ${ }^{*}$ T. HONDA,* \\ H. TAKEHANA* and T. YATSUZUKA*
}

\begin{abstract}
Introductory
The main objective in giving a patient of edentulous jaws a prosthetic treatment by means of a full denture lies in promoting his masticatory function, articulation and aesthetic appearance of his facial features. Besides these, it should be perfected in such a manner as to enable the mandibular joints of a patient to carry out the physiological functions adapted to his mandibular movement (the so-called occlusal movement). The present report deals with a patient who was installed with a full denture 7 or 8 years ago but with a damage of $32 \mid 34$ artificial teeth about 3 years later, habitual malocclusion gradually set in thereby imparing his normal mandibular movement, with the joint socket and apophysis out of right alignment. After fully examining the right and left positions of central occlusion, condyle path and incisor path, etc., the correct alignment has been successfully effected on his full denture through an application of OKINO anatomical articulator. This case serves as an illustration where a prosthetic treatment on the full denture has restored the facial features, articulation, masticatory function and hearing function completely.
\end{abstract}

\section{Case Report}

Case :

a. Name, age and sex.

b. Family history.

c. Chief complaint.

d. Previous history.

e. Present findings.
T. I., 70 years old, male

Nothing of noteworthy nature

Adjustment on malocclusion of a full denture

The patient was installed with a full denture 7 or 8 years. However, 2 or 3 years later 2 of the anterior teeth on both sides were lost and this led to a malocclusion, inarticulation, unstable denture base and poor facial features.

1. General findings.

The patient is of medium stature and his nutritional level is par. Being $152 \mathrm{~cm}$ tall, he is slender in build.

\footnotetext{
* 跣見一郎, 大木一三，小山 正宏，本田 仁夫，竹花一，八塚忠孝： Dept. of Prosthetics, Nihon Univ. School of Dentistry (Director: Prof. Setsuzo OKINO)
} 
2. Facial findings.

Front view:

In the central occlusion, the anterior teeth bite in contraocclusion, his naso-labial furrow and mento-labial furrow appear clear apparently with the furrow badly out of alignment. As the furrow width is large his mouth seems unusually wide. His lower lip protrudes and this gives him a senile appearance (Figs. 1A and 1B).

Side view:

In rest position of mandibula, his lip appearance is normal (Fig. $2 \mathrm{~B}$ ). In the central occlusion, his lower jaw and lip protrude and give the so-called contraocclusion face (Fig. $2 \mathrm{~B}$ ).

\section{Oral findings.}

Upper jaw:

The gingiva in the area of the anterior teeth has an appearance of flabby gum but around the molars it is elastic with the normal color. No irregularities are found in regard to the frenulums of lips and cheeks.

Lower jaw :

Because of the fact that the patient have his alveolar pyorrhea teeth extracted and that the adaptation of the denture base was not good, the bone has been absorbed and the flabby gum is observed all over the lower lip. Although no irregularities are found regarding the frenulums of lips and cheeks, the frenulum of tongue is somewhat elevated and a high degree of tension is observed around it. Contraocclusion is developed and the inter-maxillar distance is $1.5 \mathrm{~cm}$.

\section{Roentgenological findings.}

The use of pantomograph revealed that when in the rest position of mandibular bone the condyle is found in the center of the joint fossa, being normal (Fig. $3 \mathrm{~A}$ ). However, a pantomographic picture in the centric occlusion with the old false full denture reveals the condyle pushed into the backward position on account of shortbite and it is nearly in contact with the back wall of the joint fossa rather than in its center (Fig. $3 \mathrm{~B}$ ).

\section{Hearing and tinnitus.}

The patient complains some ringing in the area as if something strikes them when he masticates food. And there is an indication that his hearing power is getting worse.

\section{Treatment Administered}

a. Impression.

As the anterior teeth of upper jaw possessed flabby gums and the molars proper elasticity, use was made of a combination impression with no pressure on the anterior teeth but with pressure on the molars. On the other hand, since the entire lower jaw was flabby gums a non-pressure impression was used.

b. Determination of Occlusion. 
As per routine technique, the height of centric occlusion was determined and necessary registrations were made :

1. Gothic arch

2. Condyle path

$$
\text { Left } 24.5^{\circ} / \text { Right } 21.0^{\circ}
$$

3. Inter-maxillary distance $2.6 \mathrm{~cm}$

(Fig. 4)

c. Arrangement of Porcelain Teeth.

In due consideration of the adaptation and stability, the regular arrangement has been effected exclusive of first premolar and we tried to bring all the teeth in contact by means of the automatic grinding method. As for the investment, the double investment was adopted.

d. Packing of Resin.

Although upper jaw presented no particular difficulty in this regard, lower jaw possessed flabby gums in its entirety and for this reason it was necessary to use a resin material' SOFTRON' (soft resin), manufactured by the G-C Co., Tokyo,

e. Preparation of False Teeth.

To begin with, a comparison was made of the old and a new one. When the old denture was installed in the oral cavity, contraocclusion was observed at a front view (Fig. $5 \mathrm{~A}$ ). On the other hand, a front view of a new plate made normal occlusion possible (Fig. 5B). Fig. 6 gives the profiles of both old and new plates. Fig. 7 shows the appearance of occlusions in the old and new plates. The occlusion in the central position with the new plate is shown by Fig. $1 \mathrm{C}$ its side view is Fig. $2 \mathrm{C}$. Pantomographic images are given on Figs. $3 \mathrm{C}$ and 8.

\section{Conclusions}

The complaint of contraocclusion under discussion by the present paper had been caused by errors in the proper determination of vertical and horizontal alveolar relationship at the time of centric bite taking. The old denture was placed in a lower position and, at the same time, it was inclined forward. These factors resulted, after the use of prolonged duration, in a habitual contraocclusion and consequently functional disturbances took place in the facial features, articulation, masticatory function and stability of the patient. The roentgenological pictures have shown that in the central position the condyle was nearly in contact with the back wall of the joint fosse socket and this led to the debilitation of hearing power.

After a treatment described above was administered to him, his articulation and masticatory function were sufficiently restored in three months. After six months, the patient regained confidence where he has no difficulty in his daily conversational intercourse. 


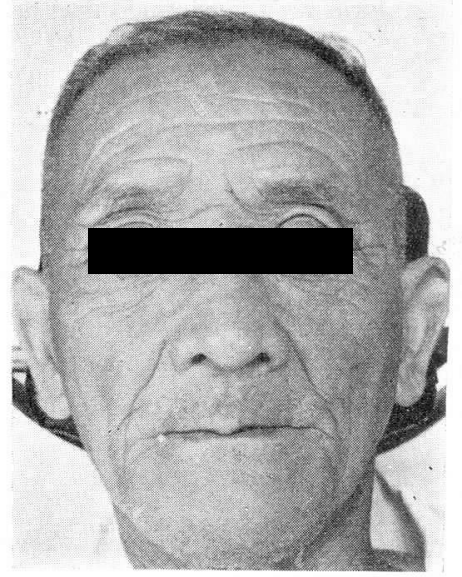

Fig. 1 A

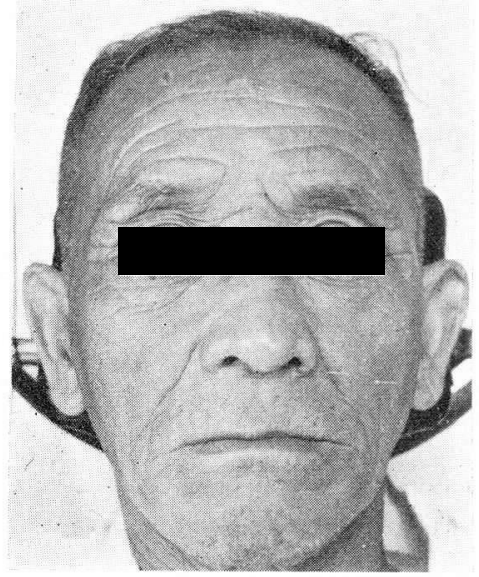

Fig. 1 B

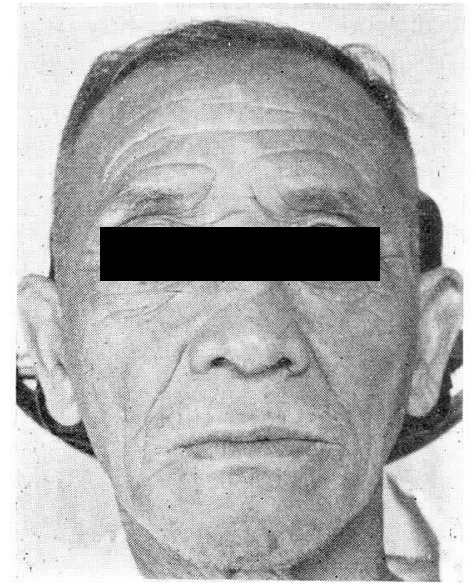

Fig. $1 \mathrm{C}$

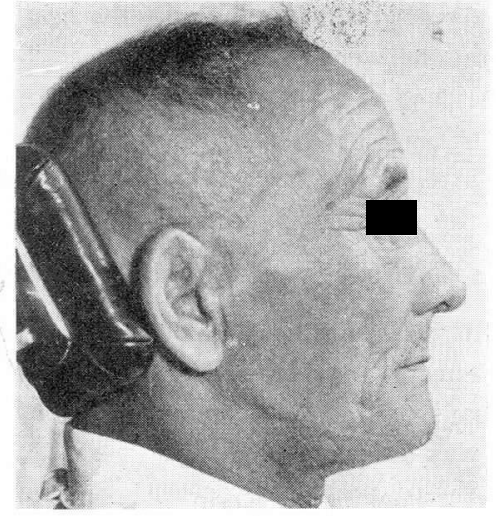

Fig. $2 \mathrm{~A}$

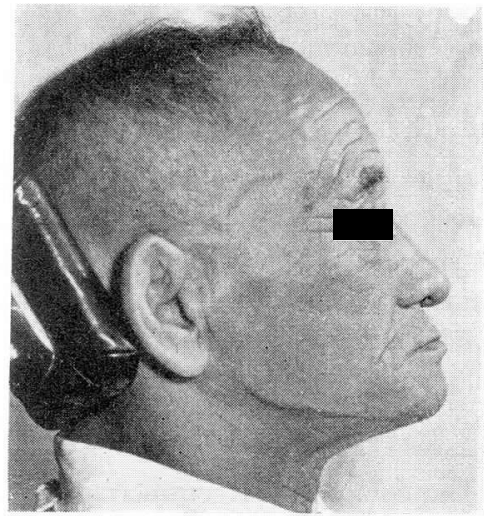

Fig. 2 B

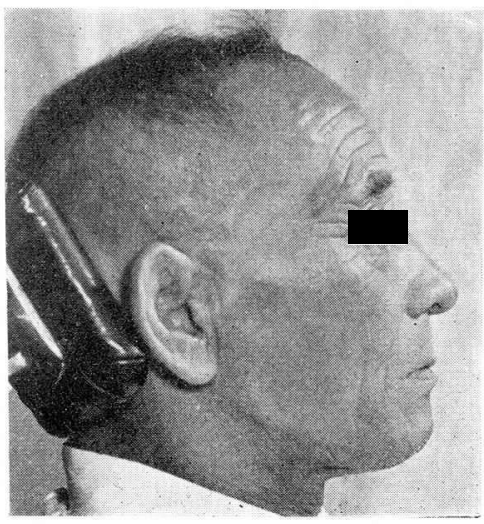

Fig. 2 C 


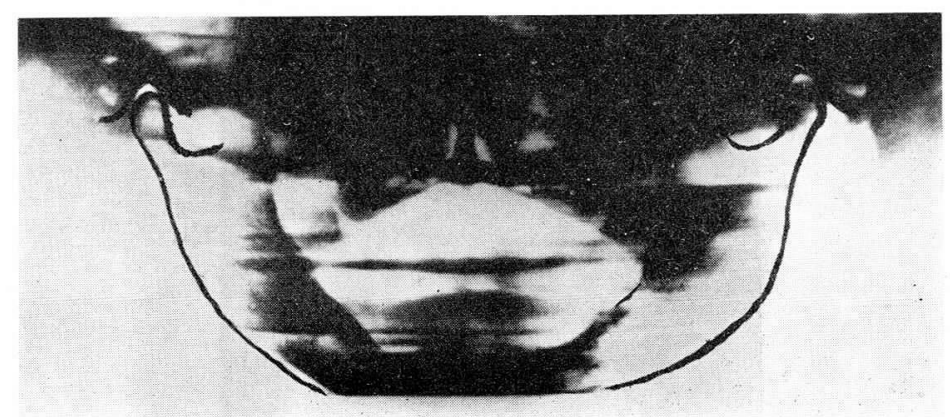

Fig. $3 \mathrm{~A}$

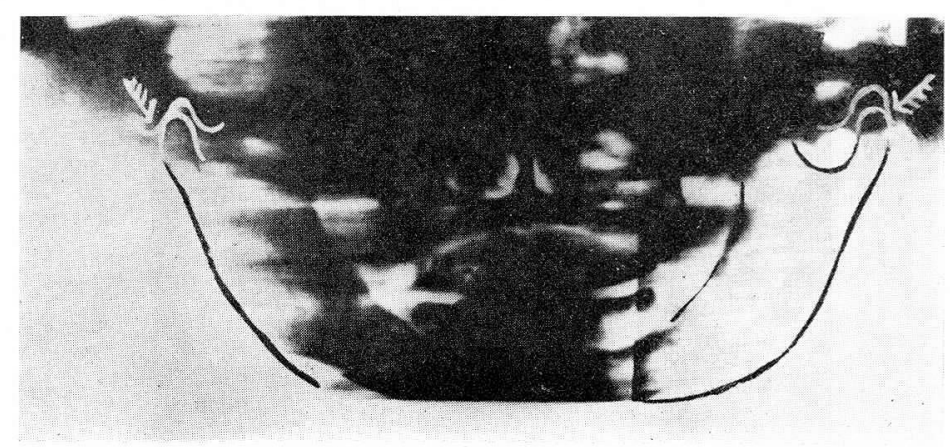

Fig. 3 B

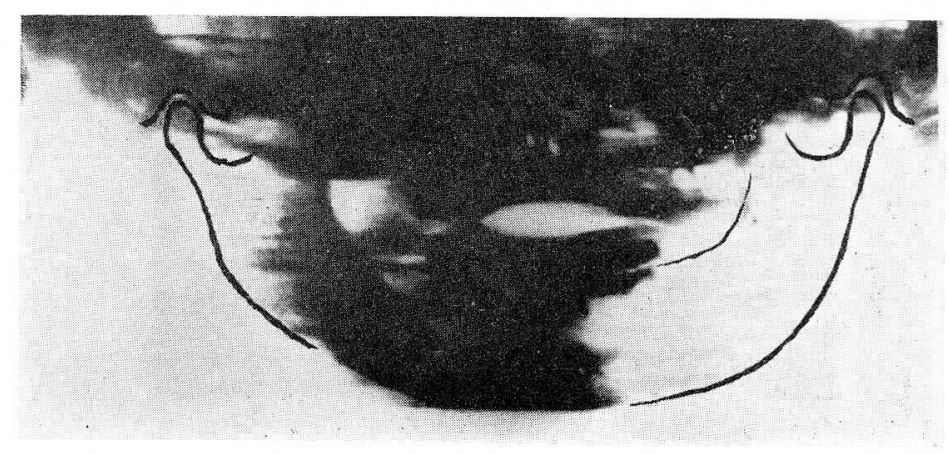

Fig. $3 \mathrm{C}$ 


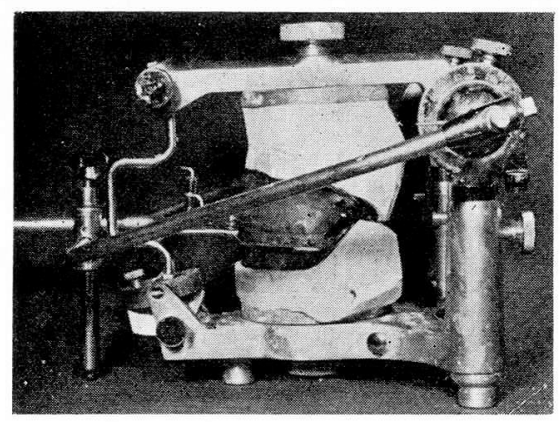

Fig. 4

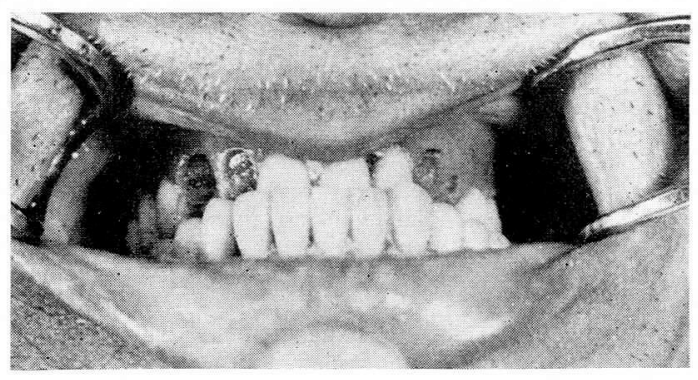

Fig. $5 \mathrm{~A}$

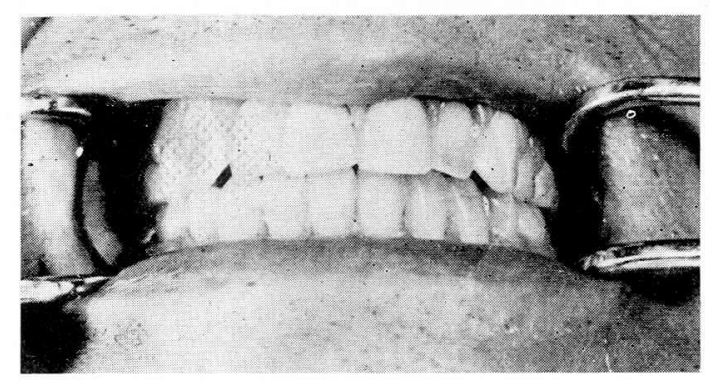

Fig. $5 \mathrm{~B}$ 


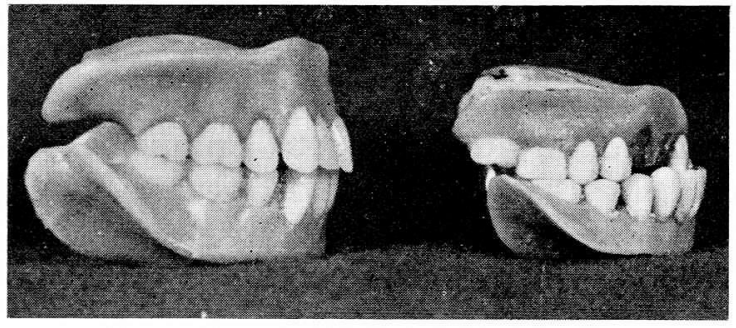

Fig. 6

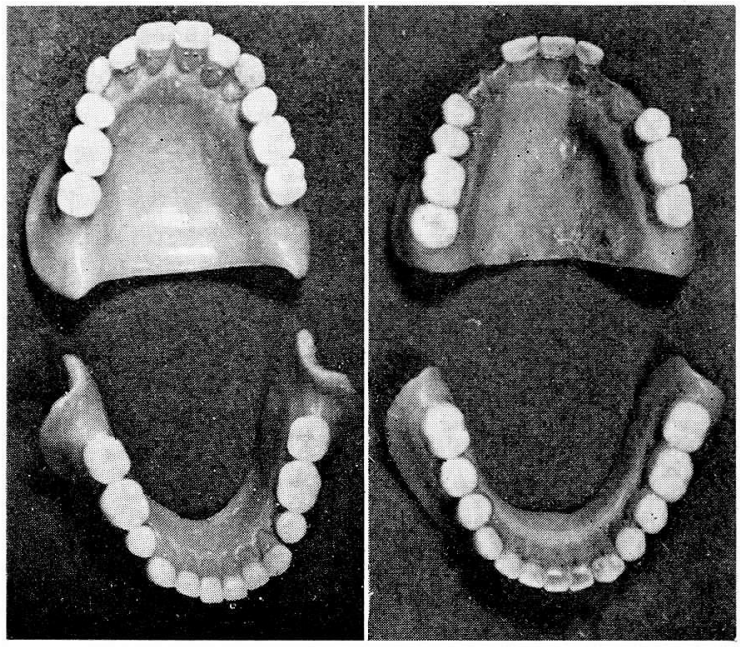

Fig. 7

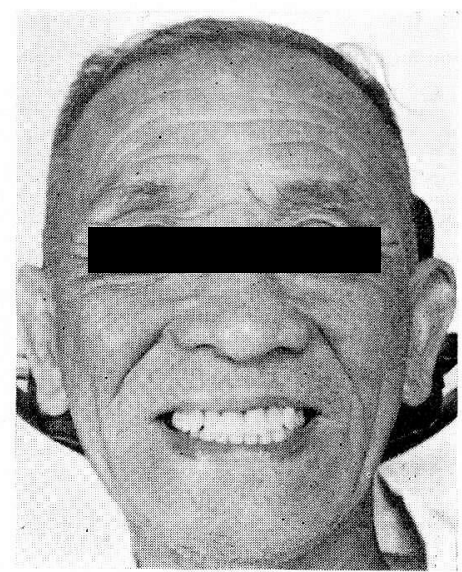

Fig. 8 